\title{
Incubation of anxiety as measured by response suppression'
}

ROGER M. TARPY ${ }^{2}$

THE COLLEGE OF WILLIAM AND MARY

Rats were given 6 days of operant bar training, 1 session of avoidance training, and differential rest intervals of 0,1 , 4,24 , and $168 \mathrm{hr}$. Ss were then tested in the operant training situation where rate suppression during avoidance CS presentation was used as an index of fear. Fear increased up to $4 \mathrm{hr}$. and diminished only slightly after 1 week.

Kamin (1957) measured the retention of an incompletely learned avoidance response. In a shuttle box, he gave his six groups avoidance training, differential retention intervals of $0,1 / 2,1,6,24 \mathrm{hr}$. , and 19 days, followed by 25 identical relearning trials, the performance during which constituted a measure of $C R$ retention. Kamin found that retention was a curvelinear function of delay with the minimum falling at $1 \mathrm{hr}$. To explain this phenomenon, now known as the "Kamin effect," he suggested two underlying processes. The decrement up to $1 \mathrm{hr}$. represents forgetting of the response while the rise in the curve after $1 \mathrm{hr}$. indicates incubation, a "jelling" of the avoidance response.

Since that time, other authors (e.g., Brush, Myer \& Palmer, 1963; Denny, 1958; Denny \& Ditchman, 1962; Denny \& Thomas, 1960, and others) have replicated the effect but have attributed the relearning decrement to response competition brought about by the disruptive effects of fear. That is, fear stimuli in the situation elicit responses (e.g., crouching) which are incompatible with the act of shuttling. Denny has suggested that fear incubates during the $1 \mathrm{hr}$. delay and subsequently dissipates whereupon relearning is not impaired at $24 \mathrm{hr}$. Following Brush (1962) it would seem useful to dichotomize the stimulus complex in avoidance conditioning into two components-the apparatus cues and the CS. Using this distinction, the apparatus cues are responsible for eliciting competing responses in the "Kamin effect." CS fear, on the other hand, as a source of motivation for the avoidance response, may incubate as well but yield a different function.

The purpose of the present study then was to test changes in CS fear over time. Although several studies have reported that incubation does occur (e.g., Brady, 1952; Bindra \& Cameron, 1953; Golin, 1961; McMichael, 1965 , and others) a systematic study of fear changes is lacking.

In order to test incubation of fear to the CS independent from those of the apparatus cues, it seemed appropriate to use a conditioned emotional response (CER). Here, the fear CS is presented in a new situation not directly related to avoidance acquisition, thus minimizing the effectiveness of irrelevant fear cues.
The extent to which ongoing habit (bar pressing) is disrupted is the index of CS fear.

\section{Subjects}

The Ss were 70 male albino rats of the Wistar strain and were purchased from the Manor Farms Breeding Colony. Estimated ages varied from 50 to 70 days, and their pre-experimental weights ranged from 195 to $300 \mathrm{gm}$. Ss were given ad lib feeding for 5 to 10 days after which they were reduced to $80 \%$ of their body weight and maintained on a $23 \mathrm{hr}$. feeding schedule. The Ss were divided into 7 groups of 10 each.

\section{Apparatus}

The operant training apparatus consisted of a modified Skinner box (Plexiglas) which contained a 2-in. bar placed 3-1/2 in. above the grid floor. To the right of the bar was a cup into which a Gerbrands food dispenser delivered $.045 \mathrm{gm}$. pellets (J.P. Noyes \& Co.). A standard 6 volt electric buzzer was centered at the base of the back wall. The entire box was placed inside a sound insulation chamber which was equipped with a $10 \mathrm{w}$. bulb for illumination and a ventilating fan. The box was wired so that food reward could be given on a variable interval (VI) or $100 \%$ schedule, or by manually operating a microswitch. The VI schedules were programmed by a Gerbrands tape puller.

The avoidance training apparatus was a tilt cage, 20 in. long, 5 in. wide, $11-1 / 2 \mathrm{in.} \mathrm{high.} \mathrm{One} \mathrm{hundred} \mathrm{gm.,} 2 \mathrm{in}$. on either side of the center pivot was sufficient to depress a microswitch located under the frame of the grid floor. The cage was also placed in a sound insulation chamber containing a fan but with no light. An identical buzzer was placed on the bottom of the back wall of the tilt cage. Procedure

On day 1 , Ss were first allowed to eat five pellets in the Skinner box followed by $1 / 2 \mathrm{hr}$. of bar shaping. On days 2 through 6 , Ss received $1 / 2 \mathrm{hr}$. per day of bar training. A VI-.25 schedule was employed on days 2 and 3 while on days 4,5 , and 6 , reinforcement occurred on a VI-.5 schedule.

On day 7 , Ss receired avoidance training in the tilt cage which consisted of $3 \mathrm{~min}$. of adaptation followed by a maximum of 30 avoidance trials. The shock intensity was $.5 \mathrm{ma}$. , the CS-US interval was 5 sec., and the intertrial interval was $1 \mathrm{~min}$. The CS, buzzer, was terminated by an avoidance crossing or at the onset of shock, whichever occurred first. An escape response terminated the shock. After a criterion of three successful avoidances in 30 trials was reached, Ss were replaced in their home cages for the inter-session interval (ISI). Five experimental groups (A) received delay intervals of $0,1,4,24$, and $168 \mathrm{hr}$. (1 week), after which time they were tested.

Two additional control groups were run. Group C-1 received 15 CS presentations in the avoidance box and had a delay interval of $1 \mathrm{hr}$. Group E-24 on the other hand received 12 unsignalled shocks (shock omitted on trials 8, 12, and 15) and had a delay of $24 \mathrm{hr}$. This procedure was followed since mean number of CS-US presentations for the experimental groups was found to be 15, mean 1st, 2nd, and 3rd avoidances appearing on trials 8,12 , and 15, respectively. All other conditions (operant training and testing) were identical for these groups.

Following the ISI, all groups were tested in the Skinner box for an additional $1 / 2 \mathrm{hr}$. The test was divided into three $10 \mathrm{~min}$. periods. During the first 10 min., no CS was presented. This period established a post-shock level of responding against which the rate for periods 2 and 3 were compared. The $5 \mathrm{sec}$. avoidance CS was then presented once per min. during periods 2 and 3 . The measure of response suppression was obtained by computing each S's rate during periods 
2 and 3 separately as a percentage of its rate during period 1 . Food was delivered on a VI-.5 schedule during the test.

\section{Results}

For all groups, mean operant rate for the last day of training, and mean number of CS-US pairings were computed. An analysis of variance was applied to each set of data separately and no significant differences were found. Differences during testing then, are presumably due to the different delay periods.

Rate for each group during period 2 is given as a mean percentage of period 1 (baseline) in Fig. 1. A Type I analysis of variance was applied to these data. The groups effect, $F=2.85, d f=6 / 63, p<.025$; the measures effect, $F=72.02, \mathrm{df}=1 / 63, \mathrm{p}<.001$; and the interaction, $F=5.26$, df $=6 / 63, p<.001$; were significant.

Using appropriate $t$ tests, it was found that for period 2, all groups differed from C-1 except E-24. A-0 and A-1 did not differ significantly from each other or from E-24. A-4 and A-24 were found to differ from all groups except A-168. Since no significant differences in suppression were found between any groups for period 3, these data are not discussed. They merely indicate that all groups recovered to their former level of responding.

\section{Discussion}

From these results, it can be concluded that fear, as measured by response suppression, increased over time up to $4 \mathrm{hr}$. and decreased only slightly after 1 week. In part, this function is similar to the one obtained in the "Kamin effect," if one may assume that Kamin's decrement represents an increase in fear. The two functions disagree, however, on the point at which fear begins to dissipate. Apparatus fear, the source of response competition in the "Kamin effect," is minimal by $24 \mathrm{hr}$. allowing effective avoidance relearning. However, fear of the CS as shown in this study does not diminish by $24 \mathrm{hr}$. The present results also disagree with McMichael (1965, exp. II). Using a similar design, he found that suppression increased

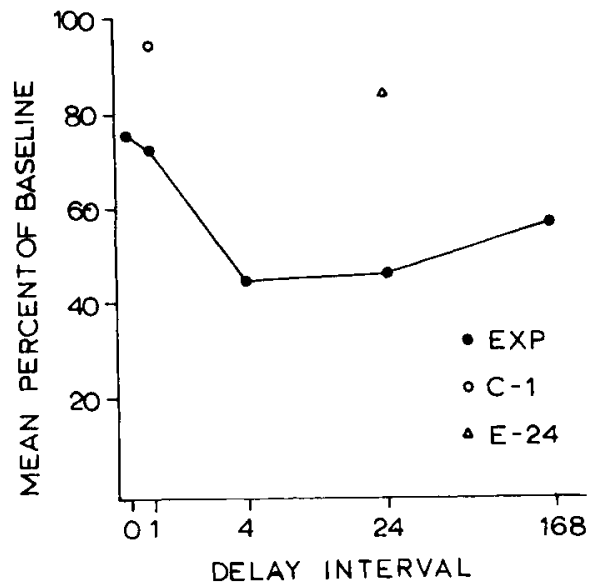

Fig. 1 Mean percentage of baseline for period 2 . up to $6 \mathrm{hr}$., but was not significantly different (from the 0-delay condition) at 24 or $504 \mathrm{hr}$.

The cause of incubation of fear is a matter of some speculation. On the basis of these results, it would be difficult to support the disinhibition theory suggested by Golin (1961) and others. Rate of avoidance learning did not vary significantly over groups nor was there any adaptation to the situation. Thus it is unlikely that differential amounts of inhibition could cause differences in suppression over groups.

The cognitive theory suggested by Saltz \& Asdourian (1963) seems equally inappropriate to account for the present results. That fear alters the stimulus situation may be the case, however, incubation of fear does not seem to be limited to generalized stimuli as indicated by the findings of Brady (1952), McMichael (1965) and the present study.

One promising series of findings was reported by Brady (1958). He found that physiological changes occurring after the psychological stress of avoidance account for ulcerations in monkeys. That acidity secretion increases during rest as a function of time would suggest that incubation of fear may be a correlate of the same physiological mechanism-acidity content itself functioning as an internal stimulus for fear.

\section{References}

Bindra, D., \& Cameron, Lois. Changes in experimentally produced anxiety with the passage of time: incubation effect. $J$. exp. Psychol., 1953, 45, 197-203.

Brady, J. V. The effect of electro-convulsive shock on a conditioned emotional response: the significance of the interval between the emotional conditioning and the electro-convulsive shock. J. comp. physiol. Psychol., 1952, 45, 9-13.

Brady, J. V. Ulcers in "executive" monkeys. Scient. American, $1958,199,95-100$.

Brush, F. R. The effects of intertrial interval on avoidance learning in the rat. J. comp. physiol. Psychol., 1962, 55, 888-892.

Brush, F. R., Myer, J. S., \& Palmer, M. E. Effects of kind of prior training and intersession interval upon subsequent avoidance learning. J. comp. physiol. Psychol., 1963, 56, 539-545.

Denny, M. R. The "Kamin effect" in avoidance conditioning. Amer. Psychologist, 1958, 13, 419. (Abstract)

Denny, M. R., \& Ditchman, R. E. The locus of maximal "Kamin effect" in rats. J. comp. physiol. Psychol., 1962, 55, 1069-1070.

Denny, M. R., \& Thomas, J. O. Avoidance learning and relearning as a function of shuttle box dimensions. Science, 1960, 132, 620-621.

Golin, S. Incubation effect: role of awareness in an immediate versus delayed test of conditioned emotionality. J. abnorm. soc. Psychol., 1961, 63, 534-539.

Kamin, L. J. The retention of an incompletely learned avoidance response. J. comp. physiol. Psychol., 1957, 50, 457-460.

McMichael, J. S. The role of fear in the retention of a conditioned avoidance response. Paper read at EPA convention, Atlantic City, April, 1965.

Saltz, E., \& Asdourian, D. Incubation of anxiety as a function of cognitive differentiation. J. exp. Psychol., 1963, 66, 17-22.

\section{Notes}

1. This study was done in partial fulfillment of the requirements for the degree of Master of Arts at the College of William and Mary. Thanks are due to Drs. P. L. Derks and H. Friedman for their thoughtful guidance and criticism.

2. Now at Princeton University. 